\title{
Design of a small size, low profile L-band antenna, optimized for space-based ADS-B signal reception
}

\author{
Jan Budroweit, Martin Drobczyk \\ Department of Avionics Systems \\ Institute of Space Systems, German Aerospace Center \\ 28359 Bremen, Germany \\ email: jan.budroweit@dlr.de
}

\begin{abstract}
Air traffic services, like the Automatic Dependent Surveillance Broadcast (ADS-B), already became a fundamental part in the civil and military aviation by the provision of aircraft tracking on ground and from space, in controlled and noncontrolled airspaces. In particular, the surveillance of aircraft from space has been identified as a trend-setting service and demand. In this paper, we present the design of a small size, low profile patch antenna, optimized for aircraft signal detection in spacecraft applications. The proposed antenna design is circularly polarized, using a single-feed configuration and it is tailored to small dimensions and the operation in a space environment.
\end{abstract}

Keywords-small size, low profile, patch antenna; ADS-B; cross-slot; Axial ratio; space application

\section{INTRODUCTION}

In the recent years the Automatic Dependent Surveillance Broadcast (ADS-B) service became essential in civil and military aviation by tracking aircraft on the ground in a controlled area and providing services to the aircraft in noncontrolled airspaces. Beyond the ground-based aircraft detection, the surveillance from space, for controlled and, particularly, non-controlled areas, has been implemented and verified by several institutions [1][2]. For scientific spacecraft, especially nanosatellites $(<10 \mathrm{~kg})$ for earth observation, size and weight are the most limiting and impacting design drivers, even for the antenna systems. Thus, an optimized antenna design for aircraft signal detection becomes mandatory, when using a space-based surveillance system. In this paper we present a proposal for a small size, low profile L-band antenna, suitable for the operation in space and optimized for the ADS-B signal reception. The design requirements and constraints are described in section II and simulation and test results are presented in section III Section IV concludes the here presented work.

\section{ANTENNA DESIGN}

ADS-B signals are transmitted in L-band at a center frequency of $1090 \mathrm{MHz}$, which equals to a wavelength of approx. $275 \mathrm{~mm}$. Using typical design guidelines for patch antennas [3][4], the outer dimension of a patch antenna results in a $\sim 140 x 140 \mathrm{~mm}$ envelope. Typically such an envelope exceeds the area, which is not available for the installation on micro satellite and CubeSat structures (max. $1 \mathrm{~kg}$ ), especially with the purpose of an antenna array configuration. Moreover, the design has to meet/match other requirements, which have to be considered for an ADS-B antenna used on a spacecraft. In this section, those requirements are explained and the design characteristics of an optimized, small size ADS-B antenna are presented.

\section{A. Design requierements}

In this sub-section the design requirements for the antenna development are presented. They include mechanical properties, electrical characteristics and the Radio Frequency (RF) performance.

\section{A. Form factor}

Since the antenna (-array) shall be installed on the structure of a micro satellite or CubeSat, the outer dimension of the antenna is limited to $90 \times 90 \times 7 \mathrm{~mm}$ (excl. connectors) envelope.

\section{B. Center frequency}

The antenna design shall possess a center frequency of $1090 \mathrm{MHz}$ in order to receive transmitted ADS-B signals from aircraft systems.

\section{Impedance and return loss}

In most cases, the receiver or RF front-end consists of a $50 \Omega$ input impedance. Thus, the best approach for the antenna feed impedance is also $50 \Omega$ in order to avoid mismatch effects and degradation of the performance. Since a real $50 \Omega$ input impedance can only be achieved in theory, the required return loss value is defined as $-10 \mathrm{~dB}$ to minimize the imbalance between the RF front end (or receiver) and the antenna. In practice, this mismatch effect is mitigated by implementing dedicated matching networks between the antenna and the input stage.

\section{Impedance bandwidth}

The ADS-B signals are transmitted with a data rate of $1 \mathrm{Mpbs}$ and the modulation scheme is the Pulse Position Modulation (PPM) [5]. Based on these specifications, a channel bandwidth of approx. $1 \mathrm{MHz}$ is required for the signal reception. The resulting $-10 \mathrm{~dB}$ bandwidth of the antenna is set to $2 \mathrm{MHz}$. In general, the Doppler-Effect needs to be taken into account, since the spacecraft is moving with a relative speed of up to $10 \mathrm{~km} / \mathrm{s}$ to the 
ground. The maximum expected frequency drift is in a range of $+/-30 \mathrm{kHz}$ and would not affect the performance, since the signal itself already occupies a bandwidth of $1 \mathrm{MHz}$.

\section{E. Gain}

The antenna design shall possess a moderate antenna gain of $>4 \mathrm{dBi}$ and a Half Power Bandwidth (HPBW) of $>100^{\circ}$ theta times $100^{\circ}$ phi to maximize the coverage and the field of view.

\section{F. Polarization}

ADS-B aircraft antennas are linearly polarized [5]. In order To avoid vertical to horizontal polarization mismatches, a circularly polarized antenna is selected. With circular polarizations on the receiver side, the mismatch loss becomes regardless to orientation and is limited to $3 \mathrm{~dB}$ if the transmit antenna is linearly polarized. Additionally, circularly polarized antennas also mitigate the effects of Faraday rotation.

\section{G. Feed configuration}

The antenna shall possess circular polarization with a single-feed configuration to avoid the need of an external polarizer. To minimize the antenna structure and design complexity, a probe-feed is preferred instead of using proximity- and aperture coupled feeds.

\section{H. Axial ratio}

To minimize performance losses, the Axial Ratio (AR) of the circular polarization shall be limited to $4 \mathrm{~dB}$ for the desired center frequency and the bandwidth of $2 \mathrm{MHz}$.

\section{Thermal stability}

Based on thermal analysis of typical micro satellite missions in a low earth orbit, the externally mounted antenna is expected to see temperatures from -20 to $70^{\circ} \mathrm{C}$. Therefore, the antenna shall resist coarse temperaturedependent changes in the dielectric constant $(<15 \mathrm{ppm} / \mathrm{K})$ and thermal expansion $(<25 \mathrm{ppm} / \mathrm{K})$ to keep the performance characteristics.

\section{J. Mechanical stress resistance}

Since the antenna is mounted outside of the satellite structure, it will be mechanically stressed, primary induced/caused by the launcher. Therefore, the antenna design must be capable to resist damages due to shock and vibrations. The loads of shock and vibrations depend on the launcher and the position on the satellite structure. To be more independent for test purposes, the General Environmental Verification Standard (GEVS) [6] is used to determine the shock and vibration loads.

\section{K. Material properties}

The materials of the antenna must have non-magnetic properties to reduce interferences with other spacecraft systems, particularly the altitude control system, which uses very sensitive magnetic sensors for the attitude determination and control. Moreover, all materials are required to be outgassing-free.

\section{B. Design characteristics}

The purpose of this antenna design is a small size circular patch, using cross-slots with unequal lengths. The presented antenna achieves a circular polarization with a single probefeed [7][8]. Thus, an external polarizer, such as a $90^{\circ}$-hybrid coupler, can be avoided and it decreases the design complexity and the final mass properties. An illustration of the described antenna configuration is presented in Fig. 1.

The selected material is a ceramic, hydrocarbon, thermoset polymer laminate, manufactured by Rogers. The substrate TMM6 with a thickness of $5.08 \mathrm{~mm}$ has excellent properties, such as: (1) a high dielectric constant of 6.3 ; (2) a thermal coefficient of expansion $(18 \mathrm{ppm} / \mathrm{K})$ and (3) a dialectical constant stability $(-11 \mathrm{ppm} / \mathrm{K})$ over a wide temperature range ($55^{\circ} \mathrm{C}$ to $\left.125^{\circ} \mathrm{C}\right)$.

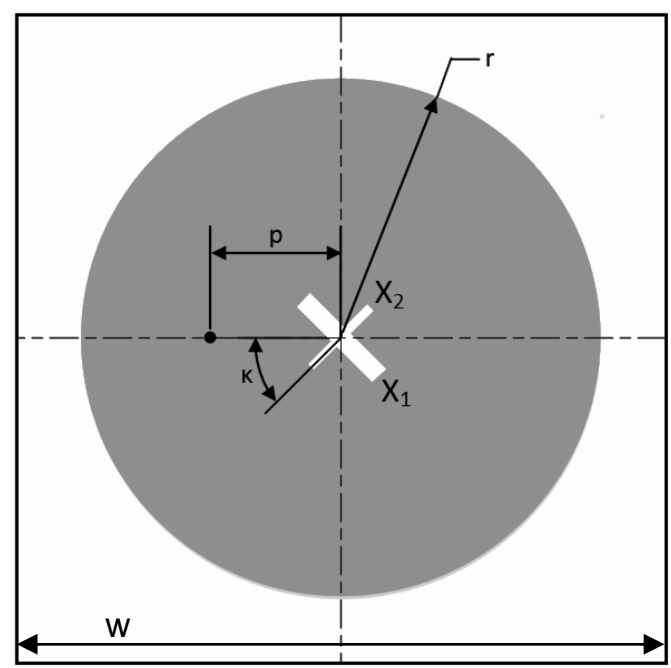

Fig. 1. Purposed antenna design with cross-slot and single probe-feed configuration for circular polarization.

The benefits of materials with a high dielectric constant and a larger thickness of the substrate are the improvement of the impedance bandwidth and the reduction of the antenna size [8][10]. Using the guidelines for a circular patch antenna design of [7]-[9], the calculated parameters are presented in Table I.

TABLE I. ANTENNA DESIGN PARAMETERS

\begin{tabular}{|l|l|c|}
\hline \multicolumn{1}{|c|}{ Name } & \multicolumn{1}{|c|}{ Value } & Unit \\
\hline dielectric constant & 6.3 & - \\
\hline Substrate thickness & 5.8 & $\mathrm{~mm}$ \\
\hline surface thickness & 35 & $\mu \mathrm{m}$ \\
\hline Surface material & EPIG & - \\
\hline Substrate size (w) & $75 \times 75$ & $\mathrm{~mm}$ \\
\hline Patch diameter (r) & 60.53 & $\mathrm{~mm}$ \\
\hline Feed position (p) & $-8.43,0$ & $\mathrm{~mm}$ \\
\hline Cross-slot length $\left(\mathrm{L}_{\mathrm{X} 1}, \mathrm{~L}_{\mathrm{X} 2}\right)$ & 24,6 & $\mathrm{~mm}$ \\
\hline Cross-slot width $\left(\mathrm{W}_{\mathrm{X} 1}, \mathrm{~W}_{\mathrm{X} 2}\right)$ & 1,1 & $\mathrm{~mm}$ \\
\hline
\end{tabular}




\begin{tabular}{|c|c|c|}
\hline Name & Value & Unit \\
\hline Cross-slot rotation angle (k) & 41 & $\circ$ \\
\hline
\end{tabular}

The cross-slots are assumed to be narrow (width $<<$ length) and the arm length depends on the desired resonant frequency [11][12]. The proper arm- and ratio lengths were optimized by using an electromagnetic simulation tool and the results are also listed in Table I. The simulation and measurement results are presented in the following section.

\section{EXPERIMENTAL RESULTS}

Based on the calculated design parameters of Table I, a simulation model was generated (refer Fig. 2). Four throughholes are implemented, one in each corner, for the mounting purpose on the spacecraft.

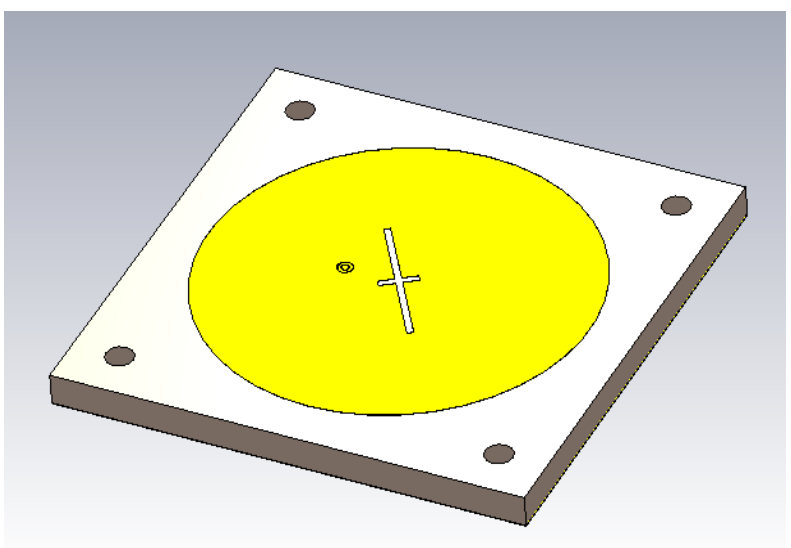

Fig. 2. 3D-Model of the designed patch antenna

The slot lengths and widths, as well as the rotation angle (k), have been optimized to achieve the best results with respect to the return loss, gain and $A R$.

\section{A. Simulation Results}

In this sub-section the simulation results of the designed crossslot patch antenna are presented.

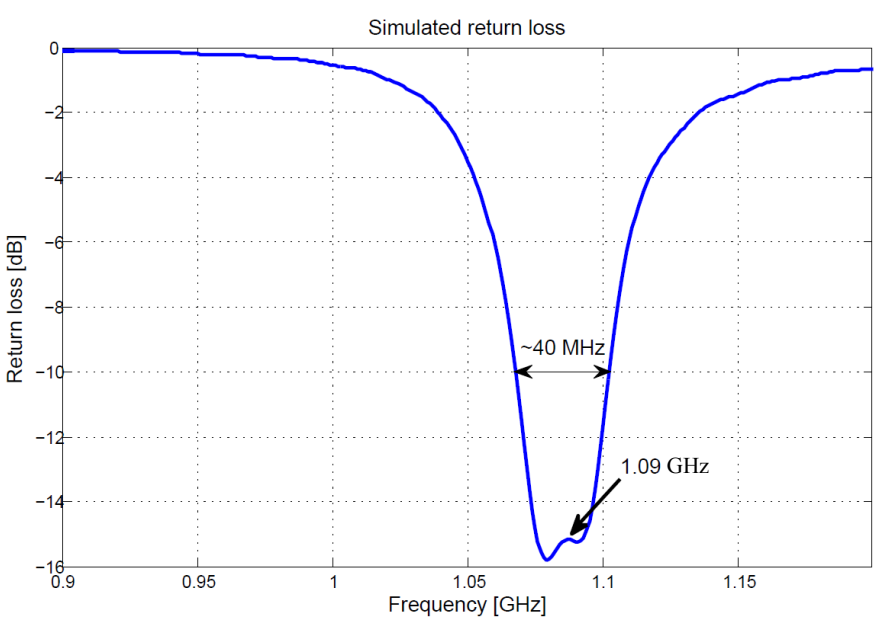

Fig. 3. Simulated return loss vs. frequency and measured impedance bandwidth
In Fig. 3 the return loss over frequency is shown. The antenna has a return loss of $-15 \mathrm{~dB}$ at the desired center frequency of $1.09 \mathrm{GHz}$ and a bandwidth of $40 \mathrm{MHz}(\sim 3.7 \%$ relative bandwidth). The simulated footprint impedance is

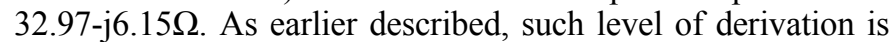
expected and an additional matching to the receiver input is required to reduce mismatching losses.

The simulated gain and AR are presented in Fig. 4. The ADS-B antenna was designed for Right Hand Circular Polarization (RHCP) and a minimal AR. The simulation results show that a boresight gain of $4.65 \mathrm{dBi}$ is achieved for RHCP. Due to the low AR of $0.4 \mathrm{~dB}$ the LHCP counterpart is reduced to $-25 \mathrm{dBi}$.
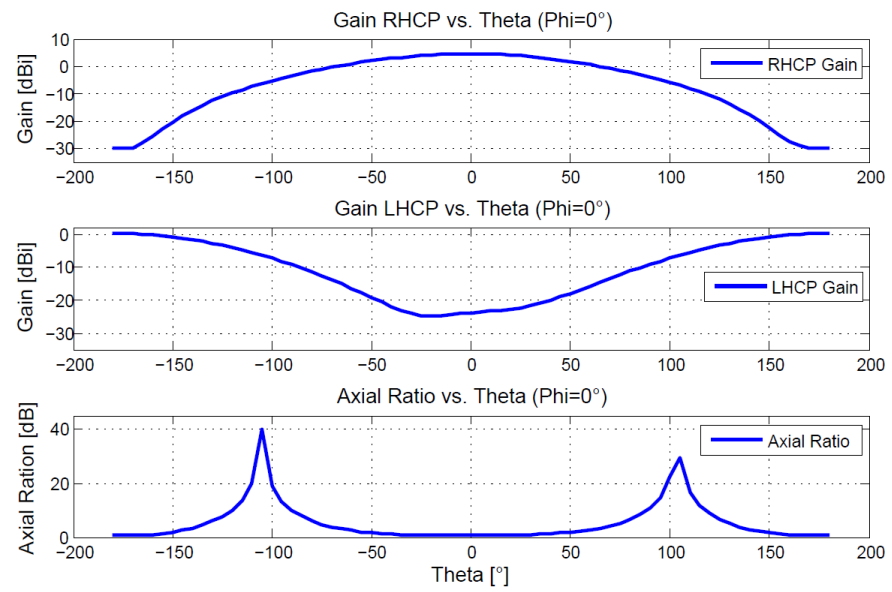

Fig. 4. Simulated circular polarized gain and axial ratio vs. theta angle (phi $=0^{\circ}$; boresight) at $1090 \mathrm{MHz}$

The RHCP gain and AR relationship to the frequency is presented in Fig. 5. As can be seen, for the desired center frequency of $1.09 \mathrm{GHz}$, the RHCP gain becomes the maximum (in boresight), at which the AR get the lowest value.
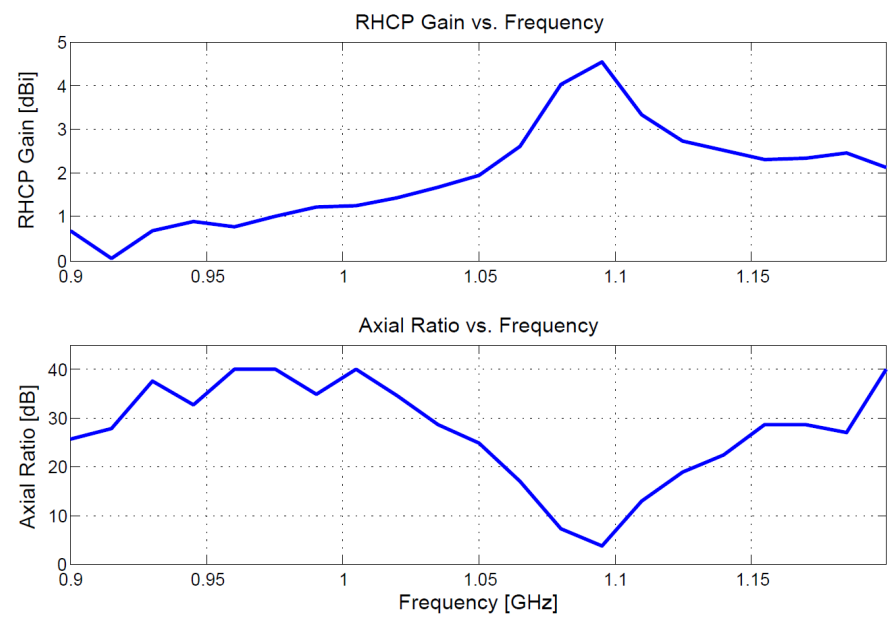

Fig. 5. Simulated RHCP gain and axial ratio vs. frequency $\left(\right.$ theta $=$ phi $=0^{\circ}$ )

To evaluate the AR-bandwidth, a closer view over a narrow frequency range is presented in Fig. 6. The simulated 3dB- 
bandwidth for the $\mathrm{AR}$ results in $8 \mathrm{MHz}$ in the boresight direction.

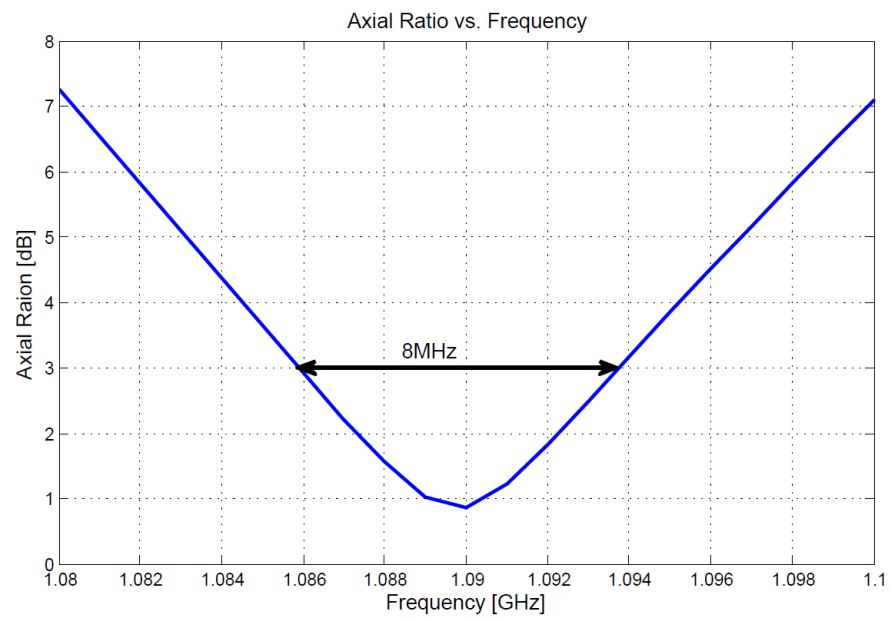

Fig. 6. Simulated axial ratio vs. frequency and measured 3dB-bandwidth in the boresight direction $\left(\right.$ theta $=\mathrm{phi}=0^{\circ}$ )

\section{B. Measurement Results}

In this sub-section the measurement results, compared to the simulation results, are presented. The measured and simulated return loss is given in Fig. 7. Compared to the simulation, the measurement results show a little drift to a lower frequency and two higher gaps. Nevertheless, the measured return loss of approx. $-15 \mathrm{~dB}$ and the impedancebandwidth of $38 \mathrm{MHz}$ are close to the simulation model.

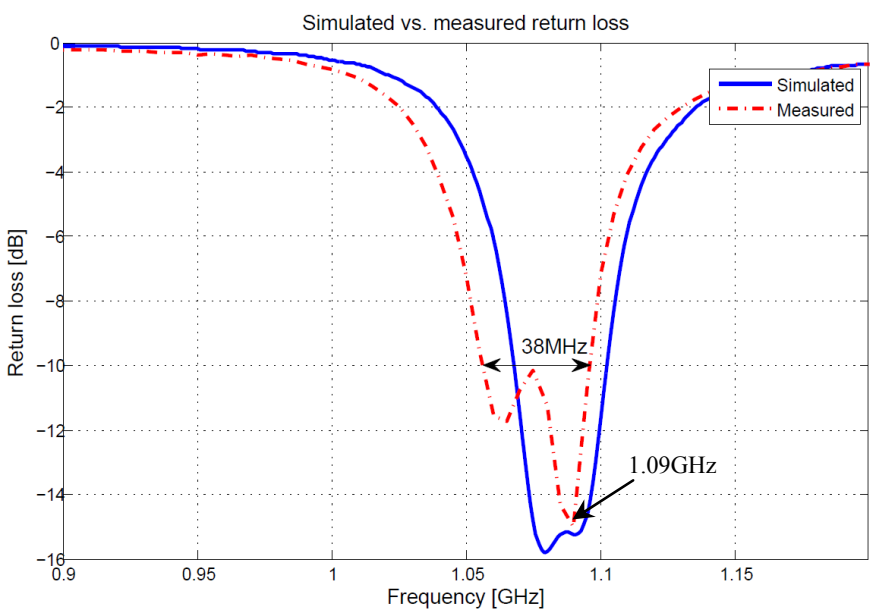

Fig. 7. Simulated and measured return loss vs. frequency and measured impedance bandwidth

For the estimation of the antenna gain, the three-antenna measurement method has been applied [13]. The selected feed and reference antenna is a linear polarized broadband hornantenna. For circularly polarized Antennas Under Test (AUT), like the proposed ADS-B patch antenna, the gain needs to be referenced to an isotopically polarized antenna. The gain for a circular polarized $\left(\mathrm{G}_{\mathrm{AUT} \text {,circular }}\right)$ AUT (given in $\mathrm{dBiC}$ ), based on the determined linear antenna gain $\left(\mathrm{G}_{\mathrm{AUT} \text {,linear }}\right)$ and a correction factor $\left(\mathrm{G}_{\mathrm{C}}\right)$, is expressed with:

$$
G_{A U T, \text { circular }}=G_{A U T, \text { linear }}+G_{c}
$$

For AUTs with circularly polarized properties, the antenna gain can be calculated with the measured AR. Therefore, the maximum and minimum received power is measured during the rotation of the feed horn-antenna across the elevation (from co- to cross-polarization). The distance describes the AR of the AUT. For perfect polarized antennas the AR is $0 \mathrm{~dB}$, which results in a gain-offset of $3 \mathrm{~dB}$ in relation to the linear measured gain. For AR-values $>0 \mathrm{~dB}$, the circularly polarized antenna gain is reduced by the gain correction factor $\left(\mathrm{G}_{\mathrm{C}}\right)$, given by the following equation:

$$
G_{c}=20 \log _{10}(0.5(1+10 \exp (-A R / 20)+3 d B
$$

The gain correction factor is also expressed in the following Fig. 8 over an AR between $0 \mathrm{~dB}$ and $40 \mathrm{~dB}$.

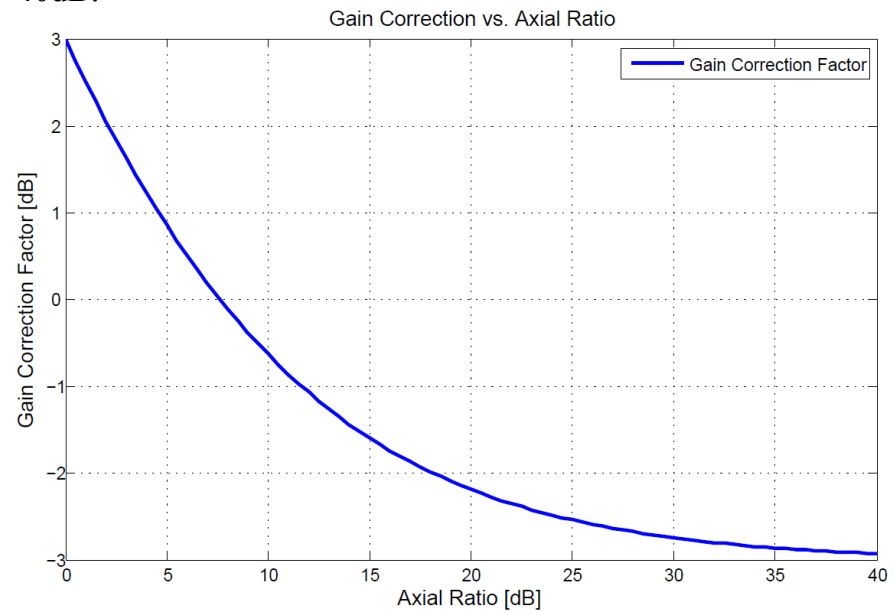

Fig. 8. Gain correction factor vs. axial ratio (0dB to $40 \mathrm{~dB})$

For the presented ADS-B patch antenna design, an AR of $2.7 \mathrm{~dB}$ has been determined, which results in a gain correction factor of $1.75 \mathrm{~dB}$.
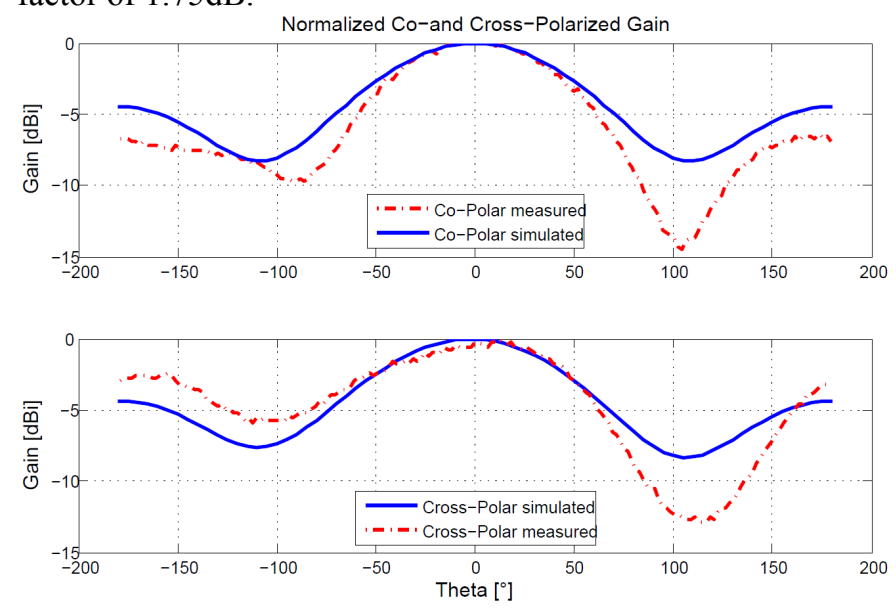

Fig. 9. Simulated and measured co- and cross-polar gain vs. theta angle (phi $=0^{\circ}$; boresight) at $1090 \mathrm{MHz}$ 
The measured and simulated far-field for co- and crosspolarization of the AUT is presented in Fig. 9. The maximum gain is normalized to $0 \mathrm{~dB}$. The measured HPBW is $\sim 101 \times 100^{\circ}$, which is slightly smaller compared to the simulation results $\left(\mathrm{HPBW}=106^{\circ}\right)$. Thus, a higher gain of the AUT can be expected. Generally, the simulation and measurement results are comparable with minor differences. These are caused by the inaccuracies of the measurement setup and the fabrication-process of the AUT.

The maximum (boresight) antenna gain of the AUT is calculated as $5.35 \mathrm{dBiC}$ using equation (1), with the measured linear gain of $3.6 \mathrm{dBi}$ and a gain correction factor of $1.75 \mathrm{~dB}$. The simulated boresight antenna gain is $4.65 \mathrm{dBiC}$.

\section{Enviromental testing}

In order to verify the mechanical stress resistance, a random vibration test has been performed. Therefore, the AUT has been mounted with four M4 screws and washers (on top of the AUT) onto a shaker facility as presented in Fig. 10. The selected screw material is stainless steel with the property of class A2-70. The torque is defined as $0.5 \mathrm{Nm}$.

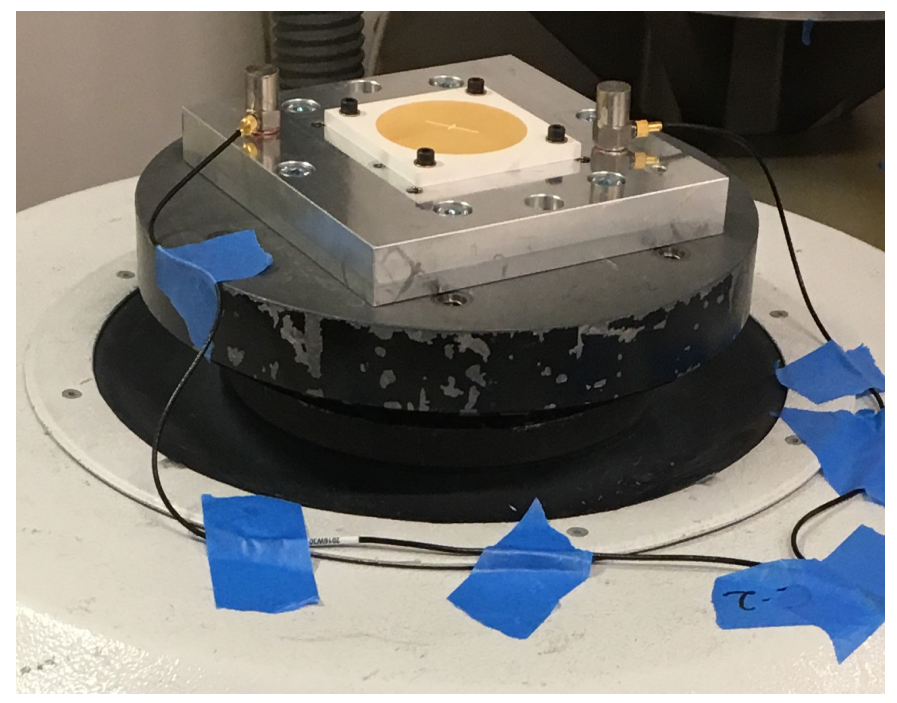

Fig. 10. ADS-B antenna at the qualification test for random vibration (z-axis)

The qualification test loads are derived from [6], which requires random vibration on all three axes with root mean square acceleration $\left(\mathrm{G}_{\mathrm{RMS}}\right)$ of $14.2 \mathrm{~g}$ for a spectrum from $20 \mathrm{~Hz}$ to $2 \mathrm{kHz}$. Each axis has been qualified in a two minute run. Low level sine-sweeps were performed prior to and after each run to identify and evaluate mechanical changes, induced by the random vibration.

During the low level sine-sweep, a resonance survey is performed as presented in Fig. 11 for the AUT in the z-axis. Both, prior to random vibration and afterwards, no resonances have been detected, which verifies the mechanical stress resistance to random vibration. Similar test results were achieved for the $\mathrm{x}$ - and $\mathrm{y}$-axis. The induced random vibration spectrum was observed over the full runtime and is presented in Fig. 12 for the z-axis.

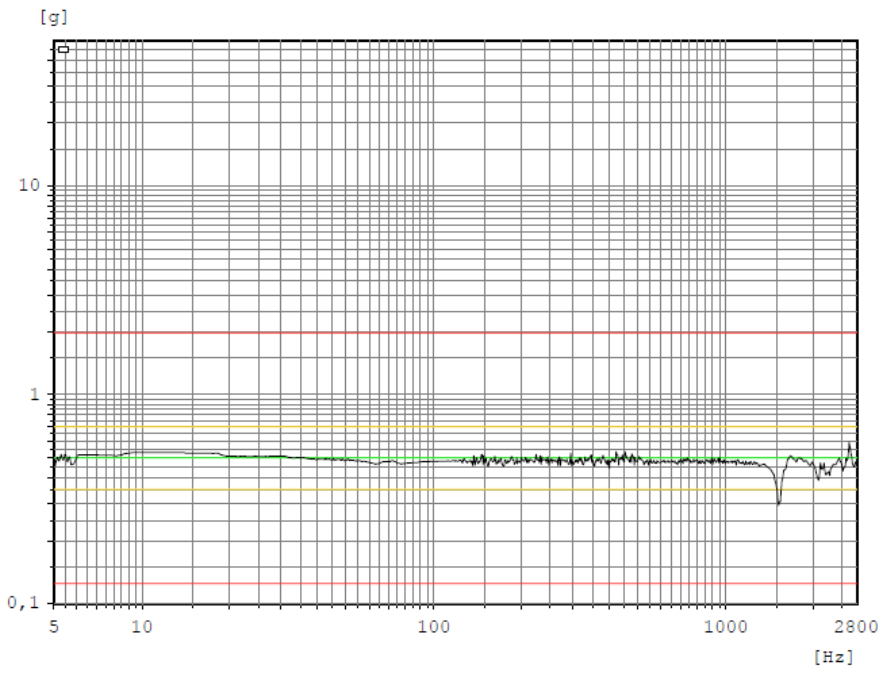

Fig. 11. Resonance survey test results $(5 \mathrm{~Hz}$ to $2.8 \mathrm{kHz})$ for the AUT in $\mathrm{z}$-axis before and after the random vibration qualification test run.

The induced and measured $\mathrm{G}_{\mathrm{RMS}}$ is $14.46 \mathrm{~g}$. Measurement results, taken for the $\mathrm{x}$ - and $\mathrm{y}$-axis, show a similar behavior.

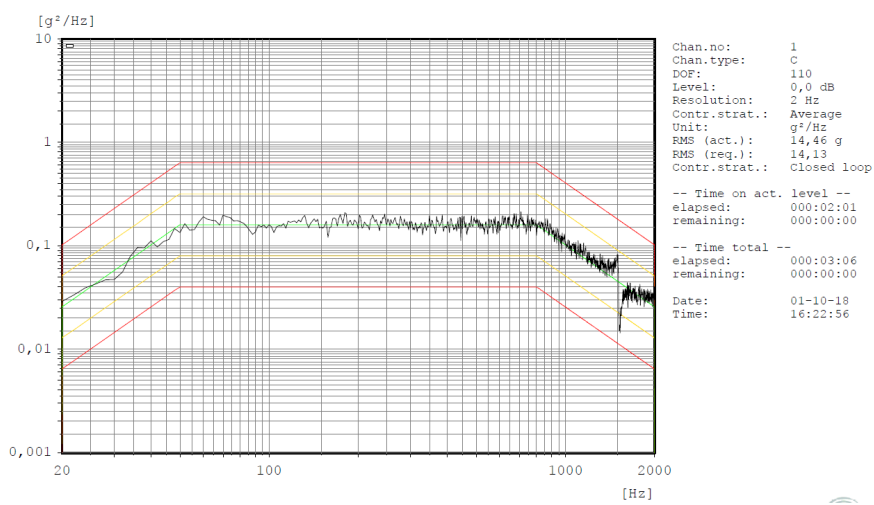

Fig. 12. Measured spectrum of the random vibration qualification test run in $\mathrm{z}$ axis for the AUT.

During the qualification test for random vibration, neither damages nor malfunctions could be identified after the visual inspection as well as after the verification by the low level sinesweeps for all three axes.

In addition to random vibration, shock tests have been performed on the AUT, which are also required for the mechanical stress resistance qualification. The required loads are also derived from the GEVS in [6]. The shock levels (green), the tolerances (red) and the measured shock response spectrum (SRS) (blue) in y-axis are presented in Fig. 13. Similar SRS were measured in $\mathrm{x}$-axis and $\mathrm{z}$-axis.

For all axes, two shocks were performed. Prior and after each shock, the AUT has been visual inspected for damages. After two shocks for one axis, the AUT has been demounted for functional test purposes and was then configured for the next axis to be tested. Part of the functional test was the return loss measurement and the impedance determination.

No malfunctions and performance degradations were observed after all. 


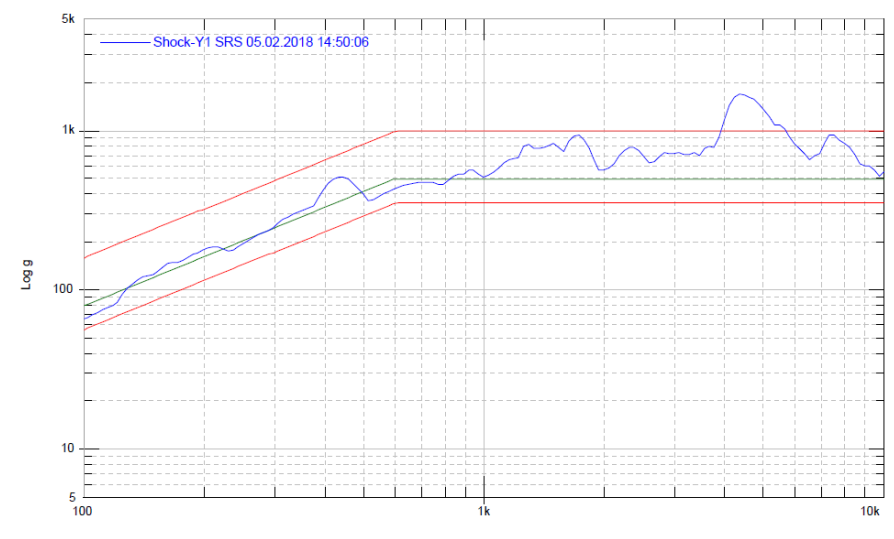

Fig. 13. Measured spectrum of the shock qualification test run in $y$-axis for the AUT.

\section{CONCLUSION}

In this paper the design of a small size, low profile L-band antenna for space-based ADS-B signal reception was presented. The design requirements for the utilization in space and the integration on a small satellite or CubeSat were discussed. Taking these aspects into account a prototype has been developed and evaluated in a measurement campaign. The measurement results show a good matching with the simulation results for the return loss, gain and HPBW. The AR differs slightly from the simulation results. These differences are expected to be caused by inaccuracies in the manufacturing process and in the measurement set-up. The mechanical stress resistance has been verified by random vibration and shock qualification tests. Further activities will include the far-field characterization, based on circularly polarized feed- and reference antennas, in order to enhance the AR determination and to perform a direct circular gain measurement of the AUT, instead of the applied linear to circular gain transformation provided by equation (1).

\section{ACKNOWLEDGMENT}

The environmental qualification tests were supported by the department of mechanical and thermal systems of the German Aerospace Center, Institute of Space Systems.

\section{REFERENCES}

[1] K. Werner, J. Bredemeyer and T. Delovski, "ADS-B over satellite: Global air traffic surveillance from space," Tyrrhenian International Workshop on Digital Communications - Enhanced Surveillance of Aircraft and Vehicles, TIWDC/ESAV 2014 6945446, pp. 47-52, 2014

[2] P. Noschese, S. Porfili and S. Di Girolamo, “ADS-B via Iridium NEXT satellites," 2011 Tyrrhenian International Workshop on Digital Communications - Enhanced Surveillance of Aircraft and Vehicles, ESAV'11 6060991, pp. 213-218, 2011

[3] J. W. Howell, "Microstrip Antennas," in IEEE International Symposium on Antennas and Propagation, Williamsburg, VA: IEEE, 1972, pp. 177 180.

[4] D. Orban and G. Moernaut, "The Basics of Patch Antennas," RF Globalnet, pp. 1-20, 2009

[5] V. A. Orlando and P. R. Drouilhet, "Mode S Beacon System: Functional Description," Project Report ATC-42 Rev. D, MIT Lincoln Laboratory, 1986.

[6] NASA Goaddard Space Flight Center, "General Environmental Verification Standard (GEVS) for GSFC Flight Programs and Projects," 2013

[7] H. Iwasaki, "A Circularly Polarized Small size Microstrip Antenna with a Cross Slot," IEEE Transaction on antennas and propagation, Vol. 44, No. 10, pp. 1399-1401, October 1996

[8] M. Albooyeh, N. Komjani, and M. Shobeyri, "A novel cross-slot geometry to improve impedance bandwidth of microstrip antennas," Progress In Electromagnetics Research Letters, Vol.4, pp. 63-72, 2008.

[9] T. Rukmini, J Shilpa, S Ravishankar, K. S. Shushrutha and S.K.Thakur, "Analysis of Circular Microstrip Patch Antenna Using Spherical Modal Expansion Technique," International Journal of Computer Applications, vol. 16, no. 5, pp. 28-34, 2011.

[10] L. C. Paul, S. Hosain, S. Sarker, M. H. Prio, M. Morshed and A. K. Sarkar, "The Effect of Changing Substrate Material and Thickness on the Performance of Inset Feed Microstrip Patch Antenna," American Journal of Networks and Communications, vol. 4(3), pp. 54-58, 2015.

[11] C. Y. Huang and K. L. Wong, "Analysis of a slot coupled cylindricalrectangular microstrip antenna," Microwave Opt. Technol. Lett. , Vol. 8, pp. 251-253, 1995.

[12] P. L. Sullivan and D. H. Schaubert, "Analysis of an aperture coupled microstrip antenna," IEEETrans. Antennas Propagat., Vol. 34, pp. 977 984, 1986.

[13] J. D. Kraus and R. J. Marhefka, "Antennas For All Applications," Mcgraw-Hill Higher Education, 3rd edition. 